\title{
Properties of The Space GFB(V, U)
}

\author{
Jehad R. Kider \\ Manar N. Gheeab \\ Department of Mathematics and Computer, Applications, School of Applied \\ Sciences, University of Technology, Baghdad, Iraq. \\ jehadkider@gmail.com_manar.naji33@gmail.com
}

Available online : $\quad 28 / 1 / 2019$

DOI: $10.29304 / j q c m .2019 .11 .1 .478$

\begin{abstract}
:
Our goal in the present paper is to recall the concept of general fuzzy normed space and its basic properties to define the general fuzzy bounded operator as a background to introduce the notion general fuzzy norm of a general fuzzy bounded linear operator. After that we proved any operator from a general fuzzy normed space into a general complete general fuzzy normed space has an extension. Also we prove that a general fuzzy bounded operator on a general fuzzy normed space is equivalent to a general fuzzy continuous. Finally different types of fuzzy approaches of operators is introduced in order to prove that the general fuzzy normed space $\mathrm{GFB}(\mathrm{V}, \mathrm{U})$ is general complete when $\mathrm{U}$ is general complete.
\end{abstract}

KeyWords: The general fuzzy normed space GFB(V,U), General Fuzzy continuous operator, General Fuzzy bounded operator, General Fuzzy normed space.

Mathematics Subject Classification: 30C45, $30 \mathrm{C50}$. 
1.Introduction. Zadeh in 1965[1] was the first one who introduced the theory of fuzzy set. When Katsaras in 1984 [2] studying the notion of fuzzy topological vector spaces he was the first researcher who studied the notion of fuzzy norm on a linear vector space. A fuzzy metric space was also studied by Kaleva and Seikkala in 1984 [3]. The fuzzy norm on a vector space have been studied by Felbin in 1992 [4] where Kaleva and Seikkala introduce this type of fuzzy metric. Another type of fuzzy metric spaces was given by Kramosil and Michalek in [5].

Certain type of fuzzy norm on a linear space was given by Cheng and Mordeson in 1994 [6] where Kramosil and Michalek present this type of fuzzy metric. A finite dimensional fuzzy normed space was studied by Bag and Samanta in 2003 [7]. Saadati and Vaezpour in 2005 [8] where studied complete fuzzy normed spaces and proved some results. Also Bag and Samanta in 2005 [9] were studied fuzzy bounded linear operators on a fuzzy normed space.

Again Bag and Samanta in 2006 and 2007 [10], [11] used the fuzzy normed spaces that introduced by Cheng and Mordeson to prove the fixed point theorems. The fuzzy topological structure that introduced by Cheng and Mordeson of the fuzzy normed space was studied by Sadeqi and Kia in 2009 [12]. Kider introduced a new fuzzy normed space in 2011 [13]. Also he proved this new fuzzy normed space has a completion in [14]. The properties of fuzzy continuous mapping which was defined on a fuzzy normed spaces by Cheng and Mordeson was studied by Nadaban in 2015 [15]. The concepts of fuzzy norm is developed by a large number of researches with different authors have been published for reference one may see [ 18, 19, $20,19,22,23,24,25]$.

In this paper first the definition of general fuzzy normrd space is recalled and also its basic properties in order to define the general fuzzy norm of a general fuzzy bounded linear operator from a general fuzzy normed space $\mathrm{V}$ into another general fuzzy normed space $\mathrm{U}$.

\section{Basic Properties of General Fuzzy Norm Definition 2.1:[10]}

A binary operation $\odot:[0,1] \times[0,1] \rightarrow[0,1]$

satisfying

(1) $\mathrm{a} \odot \mathrm{b}=\mathrm{b} \odot \mathrm{a}$

(2) $b \odot 1=b$

(3) $\mathrm{a} \odot[\mathrm{b} \odot \mathrm{t}]=[\mathrm{a} \odot \mathrm{b}] \odot \mathrm{t}$

(4) if $\mathrm{b} \leq \mathrm{a}$ and $\mathrm{t} \leq \mathrm{s}$ then $\mathrm{b} \odot \mathrm{t} \leq \mathrm{a} \odot \mathrm{s}$.

for all a $, \mathrm{b}, \mathrm{s}, \mathrm{t} \in[0,1]$ is called a continuous

\section{triangular norm [or t-norm].}

\section{Example 2.2:[11]}

(1)Let $m \otimes n=m$. $n$ for all $n, m \in[0,1]$ where $m$.n is multiplication in $[0,1]$. Then $\otimes$ is continuous tnorm.

(2)Let $m \otimes n=m \wedge n$ for all $n, m \in[0,1]$ then $\otimes$ is continuous t-norm.

\section{Remark 2.3:[24]}

(1)for all $\mathrm{n}>\mathrm{m}$ there is $\mathrm{k}$ with $\mathrm{n} \otimes \mathrm{k} \geq \mathrm{m}$ where $\mathrm{n}$, $\mathrm{m}, \mathrm{k} \in[0,1]$.

(2)there is $q$ with $q \otimes q \geq n$ where $n, q \in[0,1]$.

First we need the following definition

Definition 2.4:[26]

Let $\mathbb{R}$ be a vector a space of real numbers over filed $\mathbb{R}$ and $\odot, \otimes$ be continuous t-norm. A fuzzy set $L_{\mathbb{R}}$ $: \mathbb{R} \times[0, \infty)$ is called fuzzy absolute value on $\mathbb{R}$ if it satisfies

(A1) $0 \leq L_{\mathbb{R}}$ (n, a) $<1$ for all a $>0$.

(A2) $L_{\mathbb{R}}(\mathrm{n}, \mathrm{a})=1 \Leftrightarrow \mathrm{n}=0$ for all a $>0$.

(A3) $L_{\mathbb{R}}(\mathrm{n}+\mathrm{m}, \mathrm{a}+\mathrm{b}) \geq L_{\mathbb{R}}(\mathrm{n}, \mathrm{a}) \odot L_{\mathbb{R}}(\mathrm{m}, \mathrm{b})$.

(A4) $L_{\mathbb{R}}(\mathrm{nm}, \mathrm{ab}) \geq L_{\mathbb{R}}(\mathrm{n}, \mathrm{a}) \otimes L_{\mathbb{R}}(\mathrm{m}, \mathrm{b})$.

(A5) $L_{\mathbb{R}}(\mathrm{n}$, .): $[0, \infty) \rightarrow[0,1]$ is continuous function of $t$.

(A6) $\lim _{a \rightarrow \infty} L_{\mathbb{R}}(\mathrm{n}, \mathrm{a})=1$.

For all $m, n \in \mathbb{R}$ and for all $a, b \in[0,1]$. Then $(\mathbb{R}$, $\left.L_{\mathbb{R}}, \odot, \otimes\right)$ is called a fuzzy absolute value space.

Example 2.5:[26]

Define $L_{\mathbb{R}}(a, t)=\frac{t}{t+|a|}$ for all $a \in \mathbb{R}$ then $L_{\mathbb{R}}$ is a fuzzy absolute value on $\mathbb{R}$ where $\mathrm{t} \odot \mathrm{s}=\mathrm{t} \cdot \mathrm{s}$ and $\mathrm{t}$ $\otimes s=t \cdot s$ for all $t, s \in[0,1]$ where $t \cdot s$ is the ordinary multiplication of $\mathrm{t}$ and $\mathrm{s}$. 
Example $2.6:[28]$

Define $L_{d}: \mathbb{R} \times[0, \infty) \rightarrow[0,1]$ by

$L_{d}(\mathrm{u}, \mathrm{a})= \begin{cases}0 & \text { if } \mathrm{a} \leq|\mathrm{u}| \\ 1 & \text { if } \mathrm{a}>|\mathrm{u}|\end{cases}$

then $L_{d}$ is a fuzzy absolute value on $\mathbb{R} . L_{d}$ is called the discrete fuzzy absolute value on $\mathbb{R}$.

Definition 2.7:[28]

Let $\mathrm{V}$ be a vector space over the filed $\mathbb{R}$ and $\odot, \otimes$ be a continuous t-norms. A fuzzy set $G_{V}: \mathrm{V} \times[0, \infty)$ is called a general fuzzy norm on $\mathbf{V}$ if it satisfies the following conditions for all $\mathrm{u}, \mathrm{v} \in \mathrm{V}$ and for all $\alpha \in \mathbb{R}, \mathrm{s}, \mathrm{t} \in[0, \infty)$ :

(G1) $0 \leq G_{V}(\mathrm{u}, \mathrm{s})<1$ for all $\mathrm{s}>0$.

(G2) $G_{V}(\mathrm{u}, \mathrm{s})=1 \Leftrightarrow \mathrm{u}=0$ for all $\mathrm{s}>0$.

(G3) $G_{V}(\alpha \mathrm{u}, \mathrm{st}) \geq L_{\mathbb{R}}(\alpha, \mathrm{s}) \otimes G_{V}(\mathrm{u}, \mathrm{t})$ for all $\alpha \neq 0$ $\in \mathbb{R}$.

(G4) $G_{V}(\mathrm{u}+\mathrm{v}, \mathrm{s}+\mathrm{t}) \geq G_{V}(\mathrm{u}, \mathrm{s}) \odot G_{V}(\mathrm{v}, \mathrm{t})$.

(G5) $G_{V}(\mathrm{u},):.[0, \infty) \rightarrow[0,1]$ is continuous function of $\mathrm{t}$.

(G6) $\lim _{t \rightarrow \infty} G_{V}(\mathrm{u}, \mathrm{t})=1$

Then $\left(\mathrm{V}, G_{V}, \odot, \otimes\right)$ is called a general fuzzy normed space.

Example 2.8:[28]

Define $G_{|.|}(\mathrm{u}, \mathrm{a})=\frac{a}{a+|u|} \quad$ for all $\mathrm{u} \in \mathbb{R}$.Then $\left(\mathbb{R}, G_{|.|}, \odot, \otimes\right)$ is a general fuzzy normed space with $\mathrm{s} \odot \mathrm{t}=\mathrm{s} . \mathrm{t}$ and $\mathrm{t} \otimes \mathrm{s}=\mathrm{t}$.s for all $\mathrm{s}, \mathrm{t} \in[0,1]$. Then $G_{|.|}$is called the standard general fuzzy norm induced by the absolute value $|$.$| .$

Example 2.9 :[28]

If $(\mathrm{V},\|\|$.$) is normed space and G_{\|.\|}: \mathrm{V} \times[0, \infty) \rightarrow$ $[0,1]$ is defined by :

$G_{\|\cdot\|}(\mathrm{u}, \mathrm{a})=\frac{a}{a+\|u\|}$ then $\left(\mathrm{V}, G_{\|.\|}, \odot, \bigotimes\right)$ is general fuzzy normed space where $\mathrm{s} \odot \mathrm{t}=\mathrm{s} \wedge \mathrm{t}$ and $\mathrm{t} \otimes \mathrm{s}=$ t. $\mathrm{s}$ for all $\mathrm{t}, \mathrm{s} \in[0,1]$. Then $G_{\|.\|}$is called the standard general fuzzy norm induced by the norm $\|\cdot\|$.

Example $2.10:[28]$

Let $(\mathrm{V},\|\|$.$) be vector space over \mathbb{R}$, define

$G_{d}(\mathrm{u}, \mathrm{t})=\left\{\begin{array}{lll}1 & \text { if } & \|u\|<t \\ 0 & \text { if } & \|u\| \geq t\end{array}\right.$

Where $\mathrm{u} \odot \mathrm{v}=\mathrm{u} \otimes \mathrm{v}=\mathrm{u} \wedge \mathrm{v}$ for all $\mathrm{u}, \mathrm{v} \in[0,1]$ and $\mathrm{u} \otimes \mathrm{v}=\mathrm{u} . \mathrm{v}$ for all $\mathrm{u}, \mathrm{v} \in[0,1]$. Then $G_{d}$ is called the discrete general fuzzy norm on $\mathrm{V}$.

Proposition 2.11:[28]

Suppose that $(\mathrm{V},\|\|$.$) is a normed space define$ $G_{V}(\mathrm{u}, \mathrm{s})=\frac{s}{s+\|u\|}$ for all $\mathrm{u} \in \mathrm{V}$ and $0<\mathrm{s}$. Then $(\mathrm{V}$, $\left.G_{V}, \odot, \otimes\right)$ is general fuzzy normed space where a $\odot \mathrm{b}=\mathrm{a} \otimes \mathrm{b}=\mathrm{a} . \mathrm{b}$ for all $\mathrm{a}, \mathrm{b} \in[0,1]$.
Lemma 2.12:[28]

$G_{V}(\mathrm{u},$.$) is a nondecreasing function of \mathrm{t}$ in the general fuzzy normed space $\left(\mathrm{V}, G_{V}, \odot, \bigotimes\right)$ for all u $\in \mathrm{V}$ this means when $0<\mathrm{t}<\mathrm{s}$ implies $G_{V}(\mathrm{u}, \mathrm{t})<$ $G_{V}(\mathrm{u}, \mathrm{s})$.

Remark 2.13:[28]

Assume the general fuzzy normed space $\left(\mathrm{V}, G_{V}, \odot, \otimes\right)$. Then for any $\mathrm{u} \in \mathrm{V}, \mathrm{s}>0,0<\mathrm{n}<1$.

1-If $G_{V}(\mathrm{u}, \mathrm{s}) \geq(1-\mathrm{n})$ we can find $0<\mathrm{t}<\mathrm{s}$ with $G_{V}(\mathrm{u}, \mathrm{t})>(1-\mathrm{n})$.

2- If $G_{V}(\mathrm{u}, \mathrm{s}) \geq(1-\mathrm{n})$ we can find $0<\mathrm{s}<\mathrm{t}$ with $G_{V}(\mathrm{u}, \mathrm{t})>(1-\mathrm{n})$.

\section{Definition 2.14:[28]}

If $\left(\mathrm{V}, G_{V}, \odot, \otimes\right)$ is a general fuzzy normed space. Then GFB $(\mathrm{u}, \mathrm{n}, \mathrm{s})=\{$

$\left.\mathrm{m} \in \mathrm{V}: \quad G_{V}(\mathrm{u}-\mathrm{m}, \mathrm{s})>(1-\mathrm{n})\right\}$ is called a general fuzzy open ball with center $u \in V$ radius $n$ and $s>0$ and GFB $[\mathrm{u}, \mathrm{n}, \mathrm{s}]=\left\{\mathrm{m} \in \mathrm{V}: G_{V}(\mathrm{u}-\mathrm{m}, \mathrm{s}) \geq(1-\mathrm{n})\right\}$ is called a general fuzzy closed ball with center $\mathrm{u} \in \mathrm{V}$ radius $\mathrm{n}$ and $\mathrm{s}>0$.

\section{Definition 2.15:[28]}

Suppose that $\left(\mathrm{V}, G_{V}, \odot, \otimes\right)$ is a general fuzzy normed space and $\mathrm{M} \subseteq \mathrm{V}$. Then $\mathrm{M}$ is called a general fuzzy open if for any $u \in M$ we can find $0<$ $\mathrm{n}<1, \mathrm{~s}>0$ with $\mathrm{FB}(\mathrm{u}, \mathrm{n}, \mathrm{t}) \subseteq \mathrm{M}$. A subset $\mathrm{W} \subseteq \mathrm{V}$ is called a general fuzzy closed set if $W^{C}$ is a general fuzzy open.

\section{Definition 2.16:[28]}

Suppose that $\left(\mathrm{V}, G_{V}, \odot, \otimes\right)$ is a general fuzzy normed space. A sequence $\left(u_{n}\right)$ in $\mathrm{V}$ is said to be general fuzzy approaches to $\mathrm{u}$ if every $0<\varepsilon<1$ and $0<\mathrm{s}$ there is $\mathrm{N} \in \mathbb{N}$ such that $G_{V}\left(u_{n}-\mathrm{u}, \mathrm{s}\right)>(1$ $-\varepsilon$ ) for every $\mathrm{n} \geq \mathrm{N}$. If $\left(u_{n}\right)$ is general fuzzy approaches to the fuzzy limit $\mathrm{u}$ we write $\lim _{n \rightarrow \infty} u_{n}=$ $\mathrm{u}$ or $u_{n} \rightarrow \mathrm{u}$. Also $\lim _{n \rightarrow \infty} G_{V}\left(u_{n}-\mathrm{u}, \mathrm{s}\right)=1$ if and only if $\left(u_{n}\right)$ is general fuzzy approaches to $u$.

\section{Definition 2.17:[28]}

Suppose that $\left(V, G_{V}, \odot, \otimes\right)$ is a general fuzzy normed space. A sequence $\left(\mathrm{v}_{\mathrm{n}}\right)$ in $\mathrm{V}$ is called a general Cauchy sequence if for each $0<r<$ $1, t>0$ there exists a positive number $\mathrm{N} \in \mathbb{N}$ such that $G_{V}\left[v_{m}-v_{n}, t\right]>(1-r)$ for all $m, n \geq N$.

\section{Definition 2.18:[28]}

Let $\left(\mathrm{V}, G_{V}, \odot, \otimes\right)$ be a general fuzzy normed space and let $\mathrm{M} \subseteq \mathrm{V}$. Then the general closure of $\mathrm{M}$ is denote by $\overline{M^{G}}$ or $\operatorname{GCL}(\mathrm{M})$ is smallest general fuzzy closed set contains $\mathrm{M}$. 


\section{Definition 2.19:[28]}

Suppose that $\left(\mathrm{V}, G_{V}, \odot, \otimes\right)$ is a general fuzzy normed space and let $\mathrm{M} \subseteq \mathrm{V}$. Then $\mathrm{M}$ is said to be general fuzzy dense in $\mathrm{V}$ if $\overline{M^{G}}=\mathrm{V}$

Lemma 2.20:[28]

If $\left(\mathrm{V}, G_{V}, \odot, \otimes\right)$ is a general fuzzy normed space and let $\mathrm{M} \subseteq \mathrm{V}$. Then $\mathrm{m} \in \overline{M^{G}}$ if and only if we can find $\left(\mathrm{m}_{\mathrm{n}}\right)$ in $\mathrm{M}$ such that $\mathrm{m}_{\mathrm{n}} \rightarrow \mathrm{m}$.

Definition 2.21:[28]

Suppose that $\left(\mathrm{V}, G_{V}, \odot, \otimes\right)$ is a general fuzzy normed space A sequence $\left(\mathrm{v}_{\mathrm{n}}\right)$ in $\mathrm{V}$ is called a general Cauchy sequence if for each $0<r<$ $1, t>0$ we can find $\mathrm{N} \in \mathbb{N}$ with $\mathrm{G}_{\mathrm{V}}\left[\mathrm{v}_{\mathrm{j}}-\mathrm{v}_{\mathrm{k}}, \mathrm{t}\right]>$ $(1-r)$ for all $\mathrm{j}, \mathrm{k} \geq \mathrm{N}$.

\section{Definition 2.22:[28]}

Let $\left(\mathrm{V}, G_{V}, \odot, \otimes\right)$ be a general fuzzy normed space. A sequence $\left(u_{n}\right)$ is said to be general fuzzy bounded if there exists $0<\mathrm{q}<1$ such that $G_{V}\left(u_{n}\right.$, s) $>(1-q)$ for all $s>0$ and $n \in \mathbb{N}$.

\section{Definition $2.23:[28]$}

Let $\left(\mathrm{V}, G_{V}, \odot, \bigotimes\right)$ and $\left(\mathrm{U}, G_{U}, \odot, \otimes\right)$ be two general fuzzy normed spaces the operator $\mathrm{S}: \mathrm{V} \rightarrow \mathrm{U}$ is called general fuzzy continuous at $v_{0} \in \mathrm{V}$ for every $\mathrm{s}>0$ and every $0<\gamma<1$ there exist $\mathrm{t}$ and there exists $\delta$ such that for all $\mathrm{v} \in \mathrm{V}$ with $\mathrm{G}_{\mathrm{V}}\left[\mathrm{v}-\mathrm{v}_{0}, \mathrm{~s}\right]>$ $(1-\delta)$ we have $\mathrm{G}_{\mathrm{U}}\left[\mathrm{S}(\mathrm{v})-\mathrm{S}\left(\mathrm{v}_{0}\right), \mathrm{t}\right]>(1-\gamma)$ if $\mathrm{S}$ is fuzzy continuous at each point $v \in V$ then $S$ is said to be general fuzzy continuous .

\section{Theorem 2.24:[28]}

Suppose that $\left(\mathrm{V}, \mathrm{G}_{\mathrm{V}}, \odot . \otimes\right)$ and $\left(\mathrm{U}, \mathrm{G}_{\mathrm{U}}, \odot, \otimes\right)$ are general fuzzy normed spaces. Then $\mathrm{S}: \mathrm{V} \rightarrow \mathrm{U}$ is a general fuzzy continuous at $u \in V$ if and only if $\mathrm{u}_{\mathrm{n}} \rightarrow \mathrm{u}$ in $\mathrm{V}$ implies $\mathrm{S}\left(\mathrm{u}_{\mathrm{n}}\right) \rightarrow \mathrm{S}(\mathrm{u})$ in $\mathrm{U}$.

\section{Definition 2.25:[28]}

Suppose that $\left(\mathrm{V}, \mathrm{G}_{\mathrm{V}}, \odot, \otimes\right)$ and $\left(\mathrm{U}, \mathrm{G}_{\mathrm{U}}, \odot, \otimes\right)$ are general fuzzy normed spaces. Let $\mathrm{T}: \mathrm{V} \rightarrow \mathrm{U}$ then $\mathrm{T}$ is called uniformly general fuzzy continuous if for $\mathrm{t}>0$ and for every $0<\alpha<1$ there is $\beta$ and there is $s>0$ with $\mathrm{G}_{U}[\mathrm{~T}(\mathrm{v})-\mathrm{T}(\mathrm{u}), \mathrm{t}]>(1-\alpha)$ whenever $G_{V}[v-u, s]>(1-\beta)$ for all $v, u \in V$.

Theorem 2.26:[28]

Suppose that $\left(\mathrm{V}, \mathrm{G}_{\mathrm{V}}, \odot, \otimes\right)$ and $\left(\mathrm{U}, \mathrm{G}_{\mathrm{U}}, \odot, \otimes\right)$ are two general fuzzy normed spaces. Let $\mathrm{T}: \mathrm{V} \rightarrow \mathrm{U}$ be uniformly general fuzzy continuous operator. If $\left(u_{n}\right)$ is a general Cauchy sequence in $\mathrm{V}$ then $\left(\mathrm{T}\left(\mathrm{u}_{\mathrm{n}}\right)\right)$ is a general Cauchy sequence in $\mathrm{U}$.

\section{Definition 2.27:[28]}

Suppose that $\left(V, G_{V}, \odot, \otimes\right)$ is a general fuzzy normed space. Then $\mathrm{V}$ is called a general complete if every general Cauchy sequence in $\mathrm{V}$ is general fuzzy approaches to a vector in $\mathrm{V}$.

\section{General Fuzzy Bounded Linear Operator}

\section{Definition 3.1 :}

Suppose that $\left(\mathrm{V}, \mathrm{G}_{\mathrm{V}}, \odot, \otimes\right)$ and $\left(\mathrm{U}, \mathrm{G}_{\mathrm{U}}, \odot, \otimes\right)$ are two general fuzzy normed spaces. The operator $S: D(S) \rightarrow U$ is called general fuzzy bounded if we can find $\alpha, 0<\alpha<1$ with

$\mathrm{G}_{\mathrm{U}}(\mathrm{Sv}, \mathrm{t}) \geq(1-\alpha) \ldots(3.1)$

for each $v \in D(S)$ and $t>0$

\section{Notation :}

Suppose that $\left(\mathrm{V}, \mathrm{G}_{\mathrm{V}}, \odot, \otimes\right)$ and $\left(\mathrm{U}, \mathrm{G}_{\mathrm{U}}, \odot, \otimes\right)$ are a general fuzzy normed spaces. Put $\operatorname{GFB}(\mathrm{V}, \mathrm{U})=$ $\left\{\mathrm{S}: \mathrm{V} \rightarrow \mathrm{U}: \mathrm{G}_{\mathrm{U}}(\mathrm{Sv}, \mathrm{t}) \geq(1-\alpha)\right\}$ with $0<\alpha<\mathbf{1}$

\section{Proposition 3.2:}

If $\left(V, G_{V}, \odot, \otimes\right)$ is a general fuzzy normed space. Then the sum of any two general fuzzy bounded subset of $\mathrm{V}$ is again general fuzzy bounded also the scalar multiple of any general fuzzy bounded subset of $\mathrm{V}$ by a real number is again a general fuzzy bounded.

\section{Proof :}

Suppose that $\mathrm{A} \subseteq \mathrm{V}, \mathrm{B} \subseteq \mathrm{V}$ are general fuzzy bounded we will prove that $\mathrm{A}+\mathrm{B}$ and $\alpha \mathrm{A}$ are general fuzzy bounded for every $\alpha \neq 0$. By our assumption $\mathrm{A}$ and $\mathrm{B}$ are general fuzzy bounded so there is $\mathrm{p}, 0<p<1$ and $\mathrm{q}, 0<q<1$ such that $\mathrm{G}_{\mathrm{V}}(\mathrm{a}, \mathrm{t}) \geq(1-\mathrm{p})$ for all $\mathrm{a} \in A$ and $t>0$ also $\mathrm{G}_{\mathrm{V}}(\mathrm{b}, \mathrm{s}) \geq(1-\mathrm{q})$ for all $b \in B$ and $s>0$. Now

$$
\begin{aligned}
\mathrm{G}_{\mathrm{V}}(\mathrm{a}+\mathrm{b}, \mathrm{t}+\mathrm{s}) & \geq \mathrm{G}_{\mathrm{V}}(a, t) \odot \mathrm{G}_{\mathrm{V}}(\mathrm{b}, \mathrm{s}) \\
& \geq(1-\mathrm{p}) \odot(1-\mathrm{q})
\end{aligned}
$$

Put $(1-\mathrm{p}) \odot(1-\mathrm{q}) \geq(1-\mathrm{r})$ for some $\mathrm{r}, 0<r<$ 1

Hence $G_{V}(a+b, t+s) \geq(1-r)$ so $A+B$ is general fuzzy bounded. Similarly $G_{V}(\alpha a, t s)=$ $\left.\mathrm{L}_{\mathbb{R}}(\alpha, \mathrm{t}) \otimes \mathrm{G}_{\mathrm{V}}(\mathrm{a}, \mathrm{s})\right) \quad$ put $\quad \mathrm{L}_{\mathbb{R}}(\alpha, \mathrm{t})=(1-\beta)$. Now choose $0<\delta<1$ with that $(1-\beta) \otimes(1-\mathrm{p}) \geq$ $(1-\delta)$. Thus $\mathrm{G}_{\mathrm{V}}(\alpha \mathrm{a}, \mathrm{ts}) \geq(1-\delta)$. Hence $\alpha \mathrm{A}$ is general fuzzy bounded

\section{Lemma 3.3 :}

Suppose that $\left(\mathrm{V}, \mathrm{G}_{\mathrm{V}}, \odot, \otimes\right)$ and $\left(\mathrm{U}, \mathrm{G}_{\mathrm{U}}, \odot, \otimes\right)$ are two general fuzzy normed spaces then $\mathrm{T}_{1}+\mathrm{T}_{2} \in \mathrm{GFB}(\mathrm{V}$, $\mathrm{U})$ and $\alpha \mathrm{T} \in \operatorname{GFB}(\mathrm{V}, \mathrm{U})$ for all $\mathrm{T}_{1}, \mathrm{~T}_{2} \in \operatorname{GFB}(\mathrm{V}, \mathrm{U})$ and $0 \neq \alpha \in \mathrm{F}$. 


\section{Proof :}

Let $T_{1}$ and $T_{2}$ be general fuzzy bounded linear operator then there is $0<r_{1}<1$ and $0<r_{2}<1$ such that $G_{U}\left(T_{1}(\mathrm{v}), \mathrm{t}\right) \geq\left(1-r_{1}\right)$ and $G_{U}\left(T_{2}(\mathrm{v}), \mathrm{t}\right) \geq\left(1-r_{2}\right)$ for any $\mathrm{v} \in \mathrm{D}\left(T_{1}\right) \cap D\left(T_{2}\right)$ and any $\mathrm{s}, \mathrm{t}>0$. Now

$$
\begin{aligned}
\left.\left.G_{U}\left(T_{1}+T_{2}\right)(\mathrm{v}), \mathrm{t}+\mathrm{s}\right)=G_{U}\left(T_{1}(v)+T_{2}(v)\right), \mathrm{t}+\mathrm{s}\right) \\
\geq G_{U}\left(T_{1}(v), t\right) \odot G_{U}\left(T_{2}(v), s\right) \\
\geq\left(1-r_{1}\right) \odot\left(1-r_{2}\right)
\end{aligned}
$$

Choose $\mathrm{r}, 0<\mathrm{r}<1$ such that

$\left(1-r_{1}\right) \odot\left(1-r_{2}\right) \geq(1-r)$

Hence $G_{U}\left[\left(T_{1}+T_{2}\right)(\mathrm{v}), \mathrm{t}+\mathrm{s}\right]>(1-\mathrm{r})$

Thus $T_{1}+T_{2}$ is general fuzzy bounded operator. Also

$\left.G_{U}(\alpha T, t s)=\mathrm{L}_{\mathbb{R}}(\alpha, \mathrm{t}) \otimes \mathrm{G}_{\mathrm{V}}(\mathrm{T}, \mathrm{s})\right)$ let $\mathrm{L}_{\mathbb{R}}(\alpha, \mathrm{t})=(1-\beta)$ and $G_{U}(\mathrm{~T}, \mathrm{~s}) \geq$

$(1-\mathrm{p})$. Now choose $0<\delta<1$ with that $(1-\beta) \otimes$ $(1-\mathrm{p}) \geq(1-\delta)$.

Hence $G_{U}(\alpha T, t s) \geq(1-\delta)$. Thus $\alpha \mathrm{T}$ is general fuzzy bounded

\section{Theorem 3.4:}

Suppose that $\left(\mathrm{V}, \mathrm{G}_{\mathrm{V}}, \odot, \otimes\right)$ and $\left(\mathrm{U}, \mathrm{G}_{\mathrm{U}}, \odot, \otimes\right)$ are two general fuzzy normed spaces. Put $\mathbf{G}(\mathbf{T}, \mathbf{t})=$ $\inf _{\mathbf{v} \in \mathbf{D}(\mathbf{T})} \mathrm{G}_{\mathrm{U}}(\mathbf{T v}, \mathbf{t})$ for all $\mathrm{T} \in \mathrm{GFB}(\mathrm{V}, \mathrm{U}), \mathrm{t}>0$. Then $[\mathrm{GFB}(V, U), G, \odot, \otimes]$ is general fuzzy normed space.

Proof :

(G1)Since $0 \leq \mathrm{G}_{\mathrm{U}}(\mathbf{T v}, \mathbf{t})<1$ with all $\mathrm{v} \in D(T)$ and $t>0$ so $0 \leq G(\mathbf{T}, \mathbf{t})<1$ for all $\mathrm{t}>0$

(G2) For all $\mathrm{t}>0, \quad G(\mathrm{~T}, \mathrm{t})=1 \Leftrightarrow$ $\inf _{v \in D(T)} G_{U}(T v, t)=1 \Leftrightarrow G_{U}(T v, t)=1$

$\Leftrightarrow \mathrm{T}(\mathrm{v})=0$ for all $\mathrm{v} \in \mathrm{D}(\mathrm{T}) \Leftrightarrow T=0$

(G3) For all $0 \neq \alpha \in \mathrm{F}$ we have

$$
\begin{aligned}
G(\alpha \mathrm{T}, \mathrm{ts}) & =\inf _{\mathrm{v} \in \mathrm{D}(\mathrm{T})} \mathrm{G}_{\mathrm{U}}(\alpha \mathrm{T}, \mathrm{ts}) \\
& \geq \inf _{\mathrm{v} \in \mathrm{D}(\mathrm{T})} \mathrm{L}_{\mathbb{R}}(\alpha, \mathrm{t}) \otimes \mathrm{G}_{\mathrm{U}}(\mathrm{T}, \mathrm{s}) \\
& =\mathrm{L}_{\mathbb{R}}(\alpha, \mathrm{t}) \otimes \inf _{\mathrm{v} \in \mathrm{D}(\mathrm{T})} \mathrm{G}_{\mathrm{U}}(\mathrm{T}, \mathrm{s}) \\
& =\mathrm{L}_{\mathbb{R}}(\alpha, \mathrm{t}) \otimes G(\mathrm{~T}, \mathrm{~s})
\end{aligned}
$$

(G4) $G\left(\mathrm{~T}_{1}+\mathrm{T}_{2}, \mathrm{t}+\mathrm{s}\right)=$

$$
\begin{aligned}
& \inf \mathrm{G}_{\mathrm{U}_{\mathrm{v} \in \mathrm{D}\left(\mathrm{T}_{1}\right) \cap \mathrm{D}\left(\left(\mathrm{T}_{2}\right)\right.}}\left(\left(\mathrm{T}_{1}+\mathrm{T}_{2}\right)(\mathrm{v}), \mathrm{t}+\mathrm{s}\right) \\
& =\inf \mathrm{G}_{\mathrm{U}_{\mathrm{v} \in \mathrm{D}\left(\mathrm{T}_{1}\right) \cap \mathrm{D}\left(\left(\mathrm{T}_{2}\right)\right.}}\left(\mathrm{T}_{1}(\mathrm{v})+\mathrm{T}_{2}(\mathrm{v}), \mathrm{t}+\mathrm{s}\right) \\
& \quad \geq \inf \mathrm{G}_{\mathrm{U}_{\mathrm{v} \in \mathrm{D}\left(\mathrm{T}_{1}\right)}}\left(\mathrm{T}_{1} \mathrm{v}, \mathrm{t}\right) \odot \inf \mathrm{G}_{\mathrm{U}_{\mathrm{v} \in \mathrm{D}\left(\mathrm{T}_{2}\right)}}\left(\mathrm{T}_{2} \mathrm{v}, \mathrm{s}\right) \\
& \quad=G\left(\mathrm{~T}_{1}, \mathrm{t}\right) \odot G\left(\mathrm{~T}_{2}, \mathrm{~s}\right)
\end{aligned}
$$

(G5) Let $\left(t_{n}\right)$ be a sequence in $[0, \infty)$ with $t_{n} \rightarrow t \in$ $[0, \infty)$ then

$\mathrm{G}_{\mathrm{U}}\left(\mathrm{Tv}, \mathrm{t}_{\mathrm{n}}\right) \rightarrow \mathrm{G}_{\mathrm{U}}(\mathrm{Tv}, \mathrm{t})$ so $G\left(\mathrm{~T}, \mathrm{t}_{\mathrm{n}}\right) \rightarrow \mathrm{G}(\mathrm{T}, \mathrm{t})$ that is $(\mathrm{T}, \bullet)$ is a continuous.

(G6) $\quad \lim _{\mathrm{t} \rightarrow \infty} G(\mathrm{~T}, \mathrm{t})=\lim _{t \rightarrow \infty} \inf \mathrm{G}_{\mathrm{U}}(\mathrm{Tv}, \mathrm{t})=$ $\inf \lim _{t \rightarrow \infty} G_{U}(T v, t)=1$
Hence $(\mathrm{GFB}(\mathrm{V}, \mathrm{U}), \mathrm{G}, \odot, \otimes)$ is general fuzzy normed space.

\section{Note 3.5 :}

We can rewrite 3.1 by :

$\mathrm{G}_{\mathrm{U}}(\mathrm{Sv}, \mathrm{t}) \geq \mathrm{G}(\mathrm{S}, \mathrm{t})$.

\section{Example 3.6 :}

Let $\mathrm{V}$ be that vector space of all polynomials on C $[0,1]$ with

$\|v\|=\max |v(x)|, x \in[0,1]$. Let

$G_{V}(\mathrm{v}, \mathrm{t})= \begin{cases}1 & \text { if }\|\mathrm{v}\|<t \\ 0 & \text { if }\|\mathrm{v}\| \geq \mathrm{t}\end{cases}$

Then by example $2.10\left(\mathrm{~V}, \mathrm{G}_{\mathrm{V}}, \odot, \otimes\right)$ is a general fuzzy normed space.

Let $\mathrm{T}: \mathrm{V} \rightarrow \mathrm{V}$ be defined by

$\mathrm{T}[\mathrm{v}(\mathrm{x})]=\mathrm{v}^{\prime}(\mathrm{x})$ then $\mathrm{T}$ is linear. Let $\mathrm{v}_{\mathrm{n}}(\mathrm{x})=\mathrm{x}^{\mathrm{n}}$ indeed $\left\|\mathrm{v}_{\mathrm{n}}\right\|=1$ so

$\mathrm{G}_{\mathrm{V}}\left[\mathrm{T}\left(\mathrm{v}_{\mathrm{n}}\right), \mathrm{t}\right]= \begin{cases}1 & \mathrm{n}<t \\ 0 & \mathrm{t} \leq \mathrm{n}\end{cases}$

Hence there is no $c, 0<c<1$ satisfies the inquality

$\mathrm{G}_{\mathrm{V}}(\mathrm{T}(\mathrm{v}), \mathrm{t}) \geq(1-\mathrm{c})$. Therefore $\mathrm{T}$ is not general fuzzy bounded.

\section{Theorem 3.7 :}

Suppose that $\left(\mathrm{V}, \mathrm{G}_{\mathrm{V}}, \odot, \otimes\right)$ and $\left(\mathrm{U}, \mathrm{G}_{\mathrm{U}}, \odot, \otimes\right)$ are general fuzzy normed spaces with $U$ is a general complete. Assume that $\mathrm{T}: \mathrm{D}(\mathrm{T}) \rightarrow \mathrm{U}$ be a linear operator and a general fuzzy bounded. Then $\mathrm{T}$ has an extension $\mathrm{S}: \overline{\mathrm{D}(\mathrm{T})} \rightarrow \mathrm{U}$ with $\mathrm{S}$ is linear and general fuzzy bounded such that $G(T, t)=G(S, t)$ for all $\mathrm{t}>0$.

Proof:

Suppose that $v \in \overline{\mathrm{D}(\mathrm{T})^{\mathrm{G}}}$ then by Lemma 2.22 there is $\left(v_{n}\right)$ in $D(T)$ such that

$\mathrm{v}_{\mathrm{n}} \rightarrow \mathrm{v}$. But $\mathrm{T}$ is linear and general fuzzy bounded we have $\mathrm{G}_{\mathrm{U}}(\mathrm{T}(\mathrm{v}), \mathrm{t}) \geq(1-\mathrm{r})$

for all $\mathrm{v} \in \mathrm{D}(\mathrm{T})$ and $t>0$ where $\mathrm{r}, 0<r<1$. Now

$$
\begin{aligned}
\mathrm{G}_{\mathrm{U}}\left[\mathrm{T} \mathrm{v}_{\mathrm{n}}-\mathrm{T} \mathrm{v}_{\mathrm{m}}, \mathrm{t}\right] & =\mathrm{G}_{\mathrm{U}}\left[\mathrm{T}\left(\mathrm{v}_{\mathrm{n}}-\mathrm{v}_{\mathrm{m}}\right), \mathrm{t}\right] \\
& \geq(1-r)
\end{aligned}
$$

Thus $\left(\mathrm{T}\left(\mathrm{v}_{\mathrm{n}}\right)\right)$ is general Cauchy sequence in $\mathrm{U}$ but by our assumption $\mathrm{U}$ is general complete so that $\left(\mathrm{T}\left(\mathrm{v}_{\mathrm{n}}\right)\right)$ fuzzy approaches to $\mathrm{u} \in \mathrm{U}$. Define $\mathrm{S}(\mathrm{v})=\mathrm{u}$. Let $\mathrm{v}_{\mathrm{n}} \rightarrow \mathrm{v}$ and $\mathrm{w}_{\mathrm{n}} \rightarrow \mathrm{v}$ then $\mathrm{y}_{\mathrm{m}} \rightarrow \mathrm{v}$ where $\left(\mathrm{y}_{\mathrm{m}}\right)=$ $\left(\mathrm{v}_{1}, \mathrm{w}_{1}, \mathrm{v}_{2}, \mathrm{w}_{2}, \ldots \ldots\right)$. Hence $\left(\mathrm{Ty}_{\mathrm{m}}\right)$ fuzzy approaches and $\left(\mathrm{Tv}_{\mathrm{n}}\right)$ and $\left(\mathrm{Tw}_{\mathrm{n}}\right)$ the two subsequences of $\left(\mathrm{Ty}_{\mathrm{m}}\right)$ will has equal limit. Hence $\mathrm{S}$ is well defined for any $v \in \overline{\mathrm{D}(\mathrm{T})^{\mathrm{G}}}$. $\mathrm{S}$ linear is clear also $S(d)=T(d)$ for every $d \in D(T)$ thus $S$ is an extension of $\mathrm{T}$. 
Now we have $G_{U}\left[T v_{n}, t\right] \geq G(T, t)$ let $n \rightarrow \infty$ then $\mathrm{Tv}_{\mathrm{n}} \rightarrow \mathrm{S}(\mathrm{v})=\mathrm{u}$ thus we obtain $\mathrm{G}_{\mathrm{U}}[\mathrm{Sv}, \mathrm{t}] \geq$ $G(T, t)$. Hence $S$ is general fuzzy bounded and $\mathrm{G}[\mathrm{S}, \mathrm{t}] \geq \mathrm{G}[\mathrm{T}, \mathrm{t}] \quad$ but $\mathrm{G}[\mathrm{S}, \mathrm{t}] \leq \mathrm{G}[\mathrm{T}, \mathrm{t}]$ by the definition of general fuzzy. Together we have $\mathrm{G}[\mathrm{S}, \mathrm{t}]=\mathrm{G}[\mathrm{T}, \mathrm{t}]$

\section{Theorem 3.8 :}

If $\left(\mathrm{V}, \mathrm{G}_{\mathrm{V}}, \odot, \otimes\right)$ and $\left(\mathrm{U}, \mathrm{G}_{\mathrm{U}}, \odot, \otimes\right)$ are general fuzzy normed spaces and let $\mathrm{T}: \mathrm{D}(\mathrm{T}) \rightarrow \mathrm{U}$ be a linear operator where $\mathrm{D}(\mathrm{T}) \subseteq \mathrm{V}$. Then $\mathrm{T}$ is general fuzzy continuous if and only if $\mathrm{T}$ is general fuzzy bounded.

\section{Proof :}

Let $\mathrm{T}$ be general fuzzy bounded and let $\varepsilon, 0<\varepsilon<$ 1 be given and $t>0$ then for every $z \in D(T)$ we have $G_{U}[T z, t] \geq(1-\varepsilon)$. Now let $y \in D(T)$ then for any choice of $0<\mathrm{r}<1$ with $\mathrm{G}_{\mathrm{V}}[\mathrm{x}-\mathrm{y}, \mathrm{s}] \geq$ $(1-r)$ which implies that

$\mathrm{G}_{\mathrm{U}}[\mathrm{Tx}-\mathrm{Ty}, \mathrm{t}]=\mathrm{G}_{\mathrm{U}}[\mathrm{T}(\mathrm{x}-\mathrm{y}), \mathrm{t}] \geq(1-\varepsilon)$. Thus $\mathrm{T}$ is general fuzzy continuous at $\mathrm{x}$. Hence $\mathrm{T}$ is general fuzzy continuous.

For the Converse let $\mathrm{T}$ be a general fuzzy continuous at any point $\mathrm{x} \in \mathrm{D}(\mathrm{T})$. Then given $\varepsilon, 0<\varepsilon<1$ and $\mathrm{t}>0$ there is $\mathrm{r}, 0<r<1$ and $\mathrm{s}>0$ with $\mathrm{G}_{\mathrm{U}}[\mathrm{Tx}-$ Ty, $\mathrm{t}]>(1-\varepsilon)$ for all $\mathrm{y} \in \mathrm{D}(\mathrm{T})$ satisfying

$\mathrm{G}_{\mathrm{V}}[\mathrm{y}-\mathrm{x}, \mathrm{s}]>(1-\mathrm{r})$. Take any $z \neq 0 \in \mathrm{V}$ and set $\mathrm{y}=\mathrm{x}+\mathrm{z}$, hence for all $\mathrm{t}>0$

$$
\begin{aligned}
& \mathrm{G}_{\mathrm{U}}(\mathrm{Tz}, \mathrm{t})=\mathrm{G}_{\mathrm{U}}[\mathrm{T}(\mathrm{y}-\mathrm{x}), \mathrm{t}] \\
&=\mathrm{G}_{\mathrm{U}}[\mathrm{Ty}-\mathrm{Tx}, \mathrm{t}]>(1-\varepsilon) .
\end{aligned}
$$

Thus $\mathrm{T}$ is general fuzzy bounded .

\section{Corollary 3.9 :}

Suppose that $\left(\mathrm{V}, \mathrm{G}_{\mathrm{V}}, \odot, \otimes\right)$ and $\left(\mathrm{U}, \mathrm{G}_{\mathrm{U}}, \odot, \otimes\right)$ are two general fuzzy normed spaces with $\mathrm{T}: \mathrm{D}(\mathrm{T}) \rightarrow \mathrm{U}$ is a linear operator where $\mathrm{D}(\mathrm{T}) \subseteq \mathrm{V}$. If $\mathrm{T}$ is a general fuzzy continuous at an arbitrary vector $\mathrm{v} \in \mathrm{D}(\mathrm{T})$ then $\mathrm{T}$ is general fuzzy continuous.

\section{Proof :-}

Assume that $\mathrm{T}$ is fuzzy continuous at $\mathrm{v} \in \mathrm{D}(\mathrm{T})$ then by Theorem 3.8, $\mathrm{T}$ is general fuzzy bounded which implies that $\mathrm{T}$ is a general fuzzy continuous.

\section{Theorem 3.10:}

Suppose that $\left(\mathrm{V}, \mathrm{G}_{\mathrm{V}}, \odot, \otimes\right)$ and $\left(\mathrm{U}, \mathrm{G}_{\mathrm{U}}, \odot, \otimes\right)$ are two general fuzzy normed spaces and assume that $\mathrm{T}: \mathrm{V} \rightarrow \mathrm{U}$ is a general fuzzy bounded operator. Then 1) $v_{n} \rightarrow v$ [where $\left.v_{n}, v \in D(T)\right]$ implies $\mathrm{Tv}_{\mathrm{n}} \rightarrow \mathrm{Tv}$

2) The kernel of $T N(T)$ is general closed .

\section{Proof :}

Since $\mathrm{T}$ is general fuzzy bounded then there is $\mathrm{r}, 0<r<1$ such that

$\mathrm{G}_{\mathrm{U}}[\mathrm{T}(\mathrm{v}), \mathrm{t}] \geq(1-\mathrm{r})$ for each $\mathrm{v} \in \mathrm{D}(\mathrm{T})$ and $\mathrm{t}>0$.

Now

$\mathrm{G}_{\mathrm{U}}\left[\mathrm{Tv}_{\mathrm{n}}-\mathrm{Tv}, \mathrm{t}\right]=\mathrm{G}_{\mathrm{U}}\left[\mathrm{T}\left(\mathrm{v}_{\mathrm{n}}-\mathrm{v}\right), \mathrm{t}\right] \geq(1-\mathrm{r})$

Therefore $\mathrm{Tv}_{\mathrm{n}} \rightarrow \mathrm{Tv}$.

2) Let $v \in \overline{\mathrm{N}(\mathrm{T})^{\mathrm{G}}}$ then we can find $\left(\mathrm{v}_{\mathrm{n}}\right)$ in $\mathrm{N}(\mathrm{T})$ with $\mathrm{v}_{\mathrm{n}} \rightarrow \mathrm{v}$.

Hence $\mathrm{Tv}_{\mathrm{n}} \rightarrow \mathrm{Tv}$ by part (1). Also $\mathrm{T}(\mathrm{v})=0$ since $T\left(v_{n}\right)=0$ so that $v \in N(T)$. Since $v \in \overline{N(T)^{G}}$ was arbitrary so $\mathrm{N}(\mathrm{T})$ is general closed.

\section{Definition 3.11 :}

Suppose that $\left(V, G_{V}, \odot, \otimes\right)$ is a general fuzzy normed space and $\left(\mathbb{R}, L_{\mathbb{R}}, \odot, \otimes\right)$ is fuzzy absolute value space $\left(\mathbb{R}, L_{\mathbb{R}}, \odot, \otimes\right)$. Then a linear function $\mathrm{f}: \mathrm{V} \rightarrow \mathbb{R}$ is called general fuzzy bounded if there exists $\sigma \in$ $(0,1)$ with $L_{\mathbb{R}}[\mathrm{f}(\mathrm{v}), \mathrm{t}] \geq(1-\sigma)$ for any $\mathrm{v} \in \mathrm{D}(\mathrm{f})$, $t>0$. Furthermore, the fuzzy norm of $f$ is

$\mathrm{L}(\mathrm{f}, \mathrm{t})=\inf L_{\mathbb{R}}(\mathrm{f}(\mathrm{v}), \mathrm{t})$

and $L_{\mathbb{R}}(\mathrm{f}(\mathrm{v}), \mathrm{t}) \geq \mathrm{L}(\mathrm{f}, \mathrm{t})$.

The proof of the next results follows directly from Theorem 3.8

\section{Corollary 3.12 :}

Suppose that $\left(\mathrm{V}, \mathrm{G}_{\mathrm{V}}, \odot, \otimes\right)$ is a general fuzzy normed space and $\left(\mathbb{R}, L_{\mathbb{R}}, \odot, \otimes\right)$ is fuzzy absolute value space. Then a linear function $\mathrm{f}: \mathrm{V} \rightarrow \mathbb{R}$ with $\mathrm{D}(\mathrm{f}) \subseteq$ $\mathrm{V}$ is general fuzzy bounded if and only $\mathrm{f}$ is general fuzzy continuous.

\section{Definition 3.13 :}

Suppose that $\left(V, G_{V}, \odot, \otimes\right)$ is a general fuzzy normed space. Then $\operatorname{GFB}(V, \mathbb{R})=\{\mathrm{f}: \mathrm{V} \rightarrow \mathbb{R}: \mathrm{f}$ is general fuzzy bounded linear \} forms a general fuzzy normed space with general fuzzy norm defined by $L(f, t)=$ $\inf L_{\mathbb{R}}(f(v), t)$ which is said to be the general fuzzy dual space of $\mathrm{V}$.

\section{Definition 3.14:}

Suppose that $\left(\mathrm{V}, \mathrm{G}_{\mathrm{V}}, \odot, \otimes\right)$ is general fuzzy normed space. A sequence $\left(v_{n}\right)$ in $V$ is general fuzzy weakly approaches if we can find $\mathrm{v} \in \mathrm{V}$ with every $h \in \operatorname{GFB}(V, \mathbb{R}) \lim _{n \rightarrow \infty} h\left(v_{n}\right)=h(v)$. This is written $\mathrm{v}_{\mathrm{n}} \rightarrow^{\mathrm{w}} \mathrm{v}$ the element $\mathrm{v}$ is said to be the weak limit to $\left(v_{n}\right)$ and $\left(v_{n}\right)$ is said to be general fuzzy approaches weakly to $\mathrm{v}$. 


\section{Theorem 3.15:}

Suppose that $\left(\mathrm{V}, \mathrm{G}_{\mathrm{V}}, \odot, \otimes\right)$ is a general fuzzy normed space and $\left(\mathrm{v}_{\mathrm{n}}\right)$ is in $\mathrm{V}$. 1. If $\mathrm{v}_{\mathrm{n}} \rightarrow \mathrm{v}$ then $\quad \mathrm{v}_{\mathrm{n}} \rightarrow{ }^{\mathrm{w}} \mathrm{v}$. 2. $\mathrm{v}_{\mathrm{n}} \rightarrow{ }^{\mathrm{w}} \mathrm{v}$ implies $\mathrm{v}_{\mathrm{n}} \rightarrow \mathrm{v}$ when dimension of $\mathrm{V}$ is finite.

Proof:

1. Since $v_{n} \rightarrow v$ so for given $t>0, \sigma \in(0,1)$ there is $\mathrm{N} \in$ with

$\mathrm{G}_{\mathrm{V}}\left[\mathrm{v}_{\mathrm{n}}-\mathrm{v}, \mathrm{t}\right]>(1-\sigma)$ for all $n \geq N$. Now for every $f \in G F B(V, R)$

$\mathrm{L}_{\mathbb{R}}\left[\mathrm{f}\left(\mathrm{v}_{\mathrm{n}}\right)-\mathrm{f}(\mathrm{v}), \mathrm{t}\right]=\mathrm{L}_{\mathbb{R}}\left[\mathrm{f}\left(\mathrm{v}_{\mathrm{n}}-\mathrm{v}\right), \mathrm{t}\right] \geq \mathrm{L}[\mathrm{f}, \mathrm{t}] . \quad$ Put $\mathrm{L}[\mathrm{f}, \mathrm{t}]=(1-\varepsilon)$

Hence $L_{\mathbb{R}}\left[f\left(v_{n}\right)-f(v), t\right]>(1-\varepsilon)$. This shows that $\mathrm{v}_{\mathrm{n}} \rightarrow^{\mathrm{w}} \mathrm{v}$.

2.Suppose that $\mathrm{v}_{\mathrm{n}} \rightarrow^{\mathrm{w}} \mathrm{v}$ and $\operatorname{dimV}=\mathrm{m}$ let $\left\{\mathrm{e}_{1}, \mathrm{e}_{2}, \ldots . \mathrm{e}_{\mathrm{m}}\right\}$ be a basis for $\mathrm{V}$ so $\mathrm{v}_{\mathrm{n}}=\alpha_{1}^{(\mathrm{n})} \mathrm{e}_{1}+$ $\alpha_{2}^{(\mathrm{n})} \mathrm{e}_{2}+\cdots \ldots \ldots+\alpha_{\mathrm{m}}^{(\mathrm{n})} \mathrm{e}_{\mathrm{m}}$ and

$v=\alpha_{1} e_{1}+\alpha_{2} e_{2}+\cdots . .+\alpha_{m} e_{m}$. But $\mathrm{f}\left(\mathrm{v}_{\mathrm{n}}\right) \rightarrow$ $\mathrm{f}(\mathrm{v})$ for every $f \in G F B(V, \mathbb{R})$ put $\mathrm{f}_{1}, \mathrm{f}_{2}, \ldots, \mathrm{f}_{\mathrm{m}}$ by: $f_{j}\left(e_{j}\right)=1$ and $f_{j}\left(e_{k}\right)=0$ when $k \neq j$.

Then $f_{j}\left(v_{n}\right)=\alpha_{j}^{(n)}$ and $f_{j}(v)=\alpha_{j}$ hence $f_{j}\left(v_{n}\right) \rightarrow$ $\mathrm{f}_{\mathrm{j}}(\mathrm{v})$ implies $\alpha_{\mathrm{j}}^{(\mathrm{n})} \rightarrow \alpha_{\mathrm{j}}$.

Now for $\mathrm{n} \geq \mathrm{N}$

$$
\begin{aligned}
& \mathrm{G}_{\mathrm{V}}\left[\mathrm{v}_{\mathrm{n}}-\mathrm{v}, \mathrm{ts}\right]=\mathrm{G}_{\mathrm{V}}\left[\sum_{j=1}^{m}\left(\alpha_{\mathrm{j}}^{(\mathrm{n})}-\alpha_{\mathrm{j}}\right) \mathrm{e}_{\mathrm{j}}, s t\right] \\
& \geq \mathrm{L}_{\mathbb{R}}\left[\alpha_{1}{ }^{(\mathrm{n})}-\alpha_{1}, \mathrm{~s}\right] \otimes \mathrm{G}_{\mathrm{V}}\left[\mathrm{e}_{1}, \frac{\mathrm{t}}{\mathrm{m}}\right] \odot \\
& \mathrm{L}_{\mathbb{R}}\left[\alpha_{2}{ }^{(\mathrm{n})}-\alpha_{2}, \mathrm{~s}\right] \otimes \mathrm{G}_{\mathrm{V}}\left[\mathrm{e}_{2}, \frac{\mathrm{t}}{\mathrm{m}}\right] \odot \ldots \ldots \odot \\
& \mathrm{L}_{\mathbb{R}}\left[\alpha_{\mathrm{n}}{ }^{(\mathrm{n})}-\alpha_{\mathrm{n}}, \mathrm{s}\right] \otimes \mathrm{G}_{\mathrm{V}}\left[\mathrm{e}_{\mathrm{n}}, \frac{\mathrm{t}}{\mathrm{m}}\right] .
\end{aligned}
$$

Put $L_{\mathbb{R}}\left[\alpha_{j}^{(n)}-\alpha_{j}, s\right]=\left(1-r_{j}\right)$ and $G_{V}\left[e_{j}, \frac{t}{m}\right]=$ $\left(1-\mathrm{q}_{\mathrm{j}}\right)$.Choose $\mathrm{r}, 0<\mathrm{r}<1$ with

$\left(1-r_{1}\right) \otimes\left(1-q_{1}\right) \odot\left(1-r_{2}\right) \otimes\left(1-q_{2}\right) \odot \quad \ldots$ $\odot\left(1-r_{n}\right) \otimes\left(1-q_{n}\right)>(1-r)$

Hence $\mathrm{G}_{\mathrm{V}}\left[\mathrm{v}_{\mathrm{n}}-\mathrm{v}, \mathrm{t}\right]{ }_{\longrightarrow}>(1-r)$ for all $\mathrm{n} \geq N$. Therefore $v_{n} \rightarrow \mathrm{v}$

\section{Definition 3.16:}

Suppose that $\left(\mathrm{V}, \mathrm{G}_{\mathrm{V}}, \odot, \otimes\right)$ and $\left(\mathrm{U}, \mathrm{G}_{\mathrm{U}}, \odot, \otimes\right)$ are two general fuzzy normed spaces. A sequence $\left(T_{n}\right)$ of operators $T_{n} \in \operatorname{GFB}(V, U)$ is said to be:

1.Uniformly operator general fuzzy approaches if there is $\mathrm{T} \in \operatorname{GFB}(\mathrm{V}, \mathrm{U})$

$\mathrm{G}\left[T_{n}-\mathrm{T}, \mathrm{t}\right] \rightarrow 1$ as $\mathrm{n} \rightarrow \infty$.

2.Strong operator general fuzzy approaches if $\left(\mathrm{T}_{\mathrm{n}} \mathrm{v}\right)$ general fuzzy approaches in $\mathrm{U}$ for every $\mathrm{v} \in$ V.
3.Weakly operator general fuzzy approaches if $\left(\mathrm{T}_{\mathrm{n}} \mathrm{v}\right)$ general fuzzy approaches weakly in $\mathrm{U}$ for every $\mathrm{v} \in \mathrm{V}$.

Definition 3.17:

Suppose that $\left(V, G_{V}, \odot, \otimes\right)$ is a general fuzzy normed space. A sequence $\left(h_{n}\right)$ with $h_{n} \in \operatorname{GFB}(V, \mathbb{R})$ is called

1)Strong general fuzzy approaches in the general fuzzy norm on $\operatorname{GFB}(\mathrm{V}, \mathbb{R})$ that is $\mathrm{h} \in G \mathrm{FB}(\mathrm{V}, \mathbb{R})$ with $\mathrm{G}\left[\mathrm{h}_{\mathrm{n}}-\mathrm{h}, \mathrm{t}\right] \rightarrow 1$ for all

$t>0$ this written $h_{n} \rightarrow h$

2)Weak general fuzzy approaches in the fuzzy absolute value on $\mathbb{R}$ that is $\mathrm{h} \in \operatorname{GFB}(\mathrm{V}, \mathbb{R})$ with $h_{n}(v) \rightarrow h(v)$ for every $v \in V$ written by $\lim _{n \rightarrow \infty} h_{n}(v)=h(v)$

Theorem 3.18 :

Suppose that $\left(\mathrm{V}, \mathrm{G}_{\mathrm{V}}, \odot, \otimes\right)$ and $\left(\mathrm{U}, \mathrm{G}_{\mathrm{U}}, \odot, \otimes\right)$ are two general fuzzy normed spaces. Then $\operatorname{GFB}(\mathrm{V}, \mathrm{U})$ is general complete when $\mathrm{U}$ is general complete.

\section{Proof :}

Let $\left(T_{n}\right)$ be a general Cauchy sequence in $\operatorname{GFB}(V$, $\mathrm{U})$. Hence for every $\varepsilon, 0<\varepsilon<1, \mathrm{t}>0$ there is a number $\mathrm{N}$ with $\mathrm{G}_{\mathrm{U}}\left[\mathrm{T}_{\mathrm{n}}-\mathrm{T}_{\mathrm{m}}, \mathrm{t}\right]$

$\geq(1-\varepsilon)$ for all $m, n \geq N$.

Now for $\mathrm{v} \in \mathrm{V}$ and $\mathrm{m}, \mathrm{n} \geq \mathrm{N}$ we have by Remark 3.5 $\mathrm{G}_{\mathrm{U}}\left[\mathrm{T}_{\mathrm{n}} \mathrm{v}-\mathrm{T}_{\mathrm{m}} \mathrm{v}, \mathrm{t}\right] \geq \mathrm{G}_{\mathrm{U}}\left[\left(\mathrm{T}_{\mathrm{n}}-\mathrm{T}_{\mathrm{m}}\right)(\mathrm{v}), \mathrm{t}\right]>(1-$ ع).....(3.3)

Now for any fixed $\mathrm{v}$ and given $\varepsilon_{v}, 0<\varepsilon_{v}<1$ and we have from (3.3)

$\mathrm{G}_{\mathrm{U}}\left[\mathrm{T}_{\mathrm{n}} \mathrm{v}-\mathrm{T}_{\mathrm{m}} \mathrm{v}, \mathrm{t}\right]>\left(1-\varepsilon_{v}\right)$ so that $\left(\mathrm{T}_{\mathrm{n}} \mathrm{v}\right)$ is a general Cauchy sequence in $U$ but $U$ is general complete hence $\left(\mathrm{T}_{\mathrm{n}} \mathrm{v}\right)$ fuzzy approaches to $\mathrm{u} \in \mathrm{U}$ that is $T_{n} v \rightarrow u$. The vector $u$ depends on $v \in V$ this defines an operator $\mathrm{T}: \mathrm{V} \rightarrow \mathrm{U}$ defined by $\mathrm{T}(\mathrm{v})=\mathrm{u}$. The operator $\mathrm{T}$ is linear since

$\mathrm{T}[\alpha \mathrm{x}+\beta \mathrm{z}]=\lim _{\mathrm{n} \rightarrow \infty} \mathrm{T}_{\mathrm{n}}[\alpha \mathrm{x}+\beta \mathrm{z}]$

$$
\begin{gathered}
=\alpha \lim _{\mathrm{n} \rightarrow \infty} \mathrm{T}_{\mathrm{n}} \mathrm{x}+\beta \lim _{\mathrm{n} \rightarrow \infty} \mathrm{T}_{\mathrm{n}} \mathrm{z} \\
=\alpha \mathrm{T}(\mathrm{x})+\beta \mathrm{T}(\mathrm{z})
\end{gathered}
$$

We will prove that $\mathrm{T}$ is general fuzzy bounded and $\mathrm{T}_{\mathrm{n}} \rightarrow \mathrm{T}$ since (3.3) is satisfied for all $\mathrm{m} \geq \mathrm{N}$ and $\mathrm{T}_{\mathrm{m}} \mathrm{v} \rightarrow \mathrm{Tv}$ we may let $\mathrm{m} \rightarrow \infty$ we have from (3.3) for every $n \geq N$ and $t>0$ where for all $v$ $\in \mathrm{V}$ we obtain

$$
\begin{aligned}
G_{U}\left[\left(T_{n}\right.\right. & -T)(v), t] \\
& =G_{U}\left[T_{n} v-\lim _{m \rightarrow \infty} T_{m} v, t\right] \\
& =\lim _{m \rightarrow \infty} G_{U}\left[\left(T_{n}-T_{m}\right)(v), t\right] \\
> & (1-\varepsilon) \ldots \ldots .(3.4)
\end{aligned}
$$

Thus $\left(\mathrm{T}_{\mathrm{n}}-\mathrm{T}\right)$ with $\mathrm{n} \geq \mathrm{N}$ is general fuzzy bounded linear but $T_{n}$ is general fuzzy bounded 
so $\mathrm{T}=\mathrm{T}_{\mathrm{n}}-\left(\mathrm{T}_{\mathrm{n}}-\mathrm{T}\right)$ is general fuzzy bounded that is $\mathrm{T} \in \mathrm{GFB}(\mathrm{V}, \mathrm{U})$ also from (2.4) we obtain by taking the infimum for all $\mathrm{v}$ $G\left(T_{n}-T, t\right) \geq(1-\varepsilon)$. for all $n \geq N$ and $t>0$ that is $\mathrm{T}_{\mathrm{n}} \rightarrow \mathrm{T}$.

The proof of the next result follows immediately from Theorem 3.18

\section{Corollary 3.19 :}

Suppose that $\left(\mathrm{V}, \mathrm{G}_{\mathrm{V}}, \odot, \otimes\right)$ is a general fuzzy normed space and $\left(\mathbb{R}, L_{\mathbb{R}}, \odot, \otimes\right)$ is fuzzy absolute value space. Then $\operatorname{GFB}(V, \mathbb{R})$ is general complete if $(\mathbb{R}$, $\left.L_{\mathbb{R}}, \odot, \otimes\right)$ is general complete.

\section{References}

[1] L. Zadeh, 1965. Fuzzy sets, Inf. Control. 8: 338353.

[2] A. Katsaras, 1984. Fuzzy topological vector spaces II, Fuzzy sets and Systems, 12: 143-154.

[3] O. Kaleva and S. Seikkala, 1984. On fuzzy metric spaces, Fuzzy sets and systems, 121: 215-229.

[4] C. Felbin, 1992. Finite dimensional fuzzy normed linear spaces, Fuzzy sets and Systems, 48: 239248.

[5] O. Kramosil and J. Michalek, 1975. Fuzzy metrics and statistical metric spaces, Kybernetika, 11: 326-334.

[6] S. Cheng and J. Mordeson, 1994. Fuzzy linear operators and fuzzy normed linear spaces, Ball. Cal. Math. Soc. 86: 429 - 436.

[7] T. Bag and S. Samanta, 2003. Finite dimensional fuzzy normed linear spaces, J. Fuzzy Math. 11(3): 687-705.

[8] R. Saadati and M. Vaezpour 2005. Some results on fuzzy Banach spaces, J. Appl. Math. and Computing. 171: 475-484.

[9] T. Bag and S. Samanta, 2005. Fuzzy bounded linear operators, Fuzzy sets and Systems, 151(3): 513-547.

[10] T. Bag and S. Samanta, 2006. Fixed point theorems on Fuzzy normed spaces, Information sciences, 176: 2910-2931.

[11] T. Bag and S. Samanta, 2007, Some fixed point theorems in fuzzy normed linear spaces, Information sciences 177: 3271-3289.

[12] I. Sadeqi and F. Kia, 2009. Fuzzy normed linear space and its topological structure, Chaos Solitions and Fractals, 40 (5): 2576-2589.
[13] J. Kider, 2011. On fuzzy normed spaces, Eng. \& Tech. Journal, 29(9):1790-1795.

[14] J. Kider, 2011. Completion of fuzzy normed spaces, Eng. \& Tech. Journal, 29(10) :2004-2012.

[15] S. Nadaban, 2015. Fuzzy continuous mapping in fuzzy normed linear spaces, I. J. Computer Communications and Control, 10 (6): 834-842.

[16] J. R. Kider and N. A. Kadhum, 2017 Properties of fuzzy norm of fuzzy bounded operators, Iraqi Journal of Science, 58(3A) : 1237-1281.

[17] H. Si, H. Cao and P. Yang, 2010. Continuity in an intuitionistic fuzzy normed

Space, Seventh I Conference on fuzzy systems and knowledge Discovery, 144-148.

[18] W. Congxin and M. Ming, 1993.

Continuity and bounded mappings between fuzzy normed spaces, Fuzzy Math, 1: 13-24.

[19] M. Goudarzi and S. Vaezpour, 2010. Best simultaneous approximation in fuzzy normed spaces, Iranian J. of Fuzzy Systems, 7: 87-69.

[20] R. Jameel, 2014. On some results of analysis in a standard fuzzy normed spaces,

M.Sc. Thesis, University of Technology, Iraq.

[21] J. R. Kider, 2012. New fuzzy normed spaces, J. Baghdad Sci. , 9: 559-564.

[22] D. Oregan and R. Saadati, 2010. L-Random and fuzzy normed spaces and classical theory, CUBO Mathematical J. 2: 71-81.

[23] J. Xiao and X. Zhu, 2004. Fuzzy normed spaces of operators and its completeness, Fuzzy sets and Systems. 133: 437-452.

[24] A. George and P. Veeramani, 1994. On some results in fuzzy metric spaces, Fuzzy sets and Systems, 64: 395-399.

[25] I. Golet, 2010. On generalized fuzzy normed spaces and coincidence theorems,

Fuzzy sets and Systems, 161: 1138-1144.

[26] Jehad R. Kider and Ahmed H. Ali. 2018. Properties of fuzzy absolute value on and properties finite dimensional fuzzy normed space. Iraqi Journal of Science, Vol. 59, No.2B, pp: 909-916.

[27] A. Amini and R. Saadati, 2004. Some properties of continuous t-norms and s-norms, Int. J. Pure Appl.Math. 16: 157-164.

[28]J. R. Kider and Manner N. Gheeab, 2018, Properties of a General Fuzzy Normed Space, Iraqi Journal of Science (To appear ). 
Jehad .R/ Manar .N

\section{خواص الفضاء GFB(V, U)

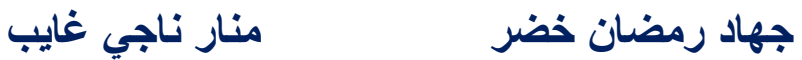 \\ الجامعة التكنولوجية / قسم العلوم التطبيقية / فرع الرياضيات وتطبيقات الحاسوب}

هدفنا في هذا البحث هو استخدام مفاهيم الفضاء القياسي الضبابي العام وخواصه الاساسية لتعريف التقيد

الضبابي العام للمؤثرات كمقدمة لتقديم مفهوم القياس الضبابي العام لمؤثر خطي مقيد ضبابيا عاما بعد ذلك برهنا ان اي مؤثر من فضاء القياس الضبايي العام الى فضاء القياس الضبابي كامل عام يمنللك نوسيع. كذللك برهنا المؤثر المقيد ضبابيا العام المعرف على فضاء القياس الضبابي العام يكافيء الاستمر ارية العامة. واخيرانواع مختلفة من التقارب الضبابي للمؤثرات نم تقديمها لغرض برهان ان فضاء القياس الضبابي العام GFB(V,U) يكون كامل عام منى ماكان U كامل عام.

الكلمات المفتاحية:فضاء القياس الضبابي العام GFB(V,U)، المؤثرات المستمرة الضبابية العامة، المؤثرات المقيدة ضبابيا العامة، فضاء القياس الضباء الفي العام. 